\section{It Takes A Village}

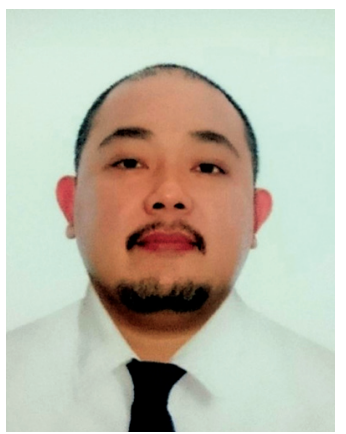

With this first issue for 2017, we are glad to announce that the Philippine Journal of Pathology is now officially a member of the Philippine Association of Medical Journal of Editors (PAMJE). Establishedin 2011 through the Philippine Council for Health Research Development of the Department of Science and Technology, the PAMJE strives to raise the quality of medical and healthrelated journal publishing in the Philippines. ${ }^{1}$ It aims to ensure the quality and dissemination of healthrelated information published in medical journals, utilized for the purposes of better-decision making and effective delivery of health services. With the PJP's inclusion, it aspires to further build capacity of its editorial team through participation in the association's activities.

My first job straight off pathology residency back in 2010 was as editorial coordinator for a regional subspecialty journal on endocrinology which was being planned to be revived. It was to be funded through society support from ASEAN member states and hosted in Manila. I remember fidgeting during my panel interview, sitting nervously in the warmly lit sala of an old house-turned-restaurant in Binondo, face to face with the future editor-in-chief and a few senior specialists who would be part of the journal's first editorial board, armed only with my amateur experience and driven by my interest in publishing.

Over the course of six years, I was provided a unique opportunity to understand and appreciate the evolving landscape of medical journals, how scientific knowledge is shared, cited and built upon by other scientists, the concept of open access, peer review and editorial deliberation, the tools that can be used to improve journal visibility and searchability, and the resources that are available to ensure that the quality of information is ethical and truthful.

Along the way, I learned how establishment and implementation of solid editorial policies based on international standards will spell the difference between a high quality medical journal and a mediocre one, and how crucial and powerful a factor online presence is in this digital age. Moreover, I realized that being trusted by readers and wouldbe authors, being eligible for indexing, and being taken seriously by funders, take not just continued, consistent efforts, but also patience and time.
Ultimately though, the valuable lessons I learned in that journal convinced me that we, Filipino pathologists, could actually replicate the publication's success, if we follow the same open-access, society support-driven paradigm which aspires to achieve international publishing standards without shortchanging the quality offered by the journal. Having learned from this journal's journey, the PJP is fortunate to start on the right track.

I am overwhelmed at, and humbled by, the financial support being provided by the Philippine Society of Pathologists, Inc for the successful revival of the PJP. This kind of support from the present leadership is encouraging and it actually takes us halfway to sustainability. To complement this, the PJP is looking into partnering with industry through sponsorships, but maintaining our stance against levying article processing fees to authors or asking for payment for subscriptions or downloading of scientific content.

In addition, the society governors and committees can update the country's research agenda for pathology and laboratory medicine, and look into creative ways of encouraging research initiatives, through research grants and calls for proposals, for example. Residency training officers can look into building capacity for the next generation of pathologists on research methods, project management, and promote submission of manuscripts. The society members, for their part, may expand support for its own journal, not only by reading published articles, providing constructive feedback, sharing their expertise as peer reviewers and editors, but more so, through submission.

All of us are enjoined to support the PJP through our different ways, through our different contributions. This second issue, the first for 2017 , is dedicated to you.

\section{Amado O. Tandoc III, MD, FPSP}

Editor-in-Chief

\section{REFERENCES}

1. Philippine Association of Medical Journal Editors Established. 2011. Available at: http://www.pchrd.dost.gov. ph/index.php/news/events/2641-philippine-association-ofmedical-journal-editors-established

https://doi.org/10.21141/PJP.2017.001 